\title{
DISCUSSION OF “THE INFLUENCE OF FIRM MATURATION ON FIRMS' RATE OF ADJUSTMENT TO THEIR OPTIMAL CAPITAL STRUCTURES”
}

\author{
by \\ Dan S. Dhaliwal \\ University of Arizona
}

and

John R. Graham

Duke University 


\section{DISCUSSION OF “THE INFLUENCE OF FIRM MATURATION ON FIRMS' RATE OF ADJUSTMENT TO THEIR OPTIMAL CAPITAL STRUCTURES”}

Though there is evidence that firms respond to debt-related tax incentives, the response does not seem particularly strong, especially among mature, profitable companies. Myers (1984) and Shevlin (1999) both argue that non-tax adjustment costs might be large enough to discourage the use of debt. Scholes and Wolfson (1989) conjecture that adjustment costs increase as a firm evolves from start-up to mature firm, thereby exerting an ever-increasing disincentive to use debt. The present paper seeks to provide evidence on whether adjustment costs increase with age during the first nine years after IPO. It does this by determining how aggressively firms move towards their "target debt ratio" each year. The authors find that movement towards the target debt ratio decreases over time, which they attribute to increasing adjustment costs.

The authors take a modest "first step" towards helping us understand adjustment costs. Though just a first step, the topic itself is very important, so a modest step represents a reasonable start. Moreover, even ignoring adjustment costs, we know little about the important issue of how debt policy evolves, so the present paper is helpful in this dimension, too.

\section{Hypothesis and Results}

Based on an exceptionally thorough literature review, the authors cite the following reasons for expecting adjustment costs to increase with age: (i) firms access capital markets less frequently as they mature; (ii) firms gradually shift from private debt towards public debt as they mature and this may undermine their capital structure flexibility. Public debt is more costly to renegotiate than private debt, and the presence of public debt in firms' capital structure also affects renegotiations with private lenders; (iii) firms gradually reduce their financing with securities that have intrinsic repayment flexibility; (iv) the evolution in firms' external financing decisions suggests that their capital structures gradually become more complex. This complexity in the capital structure is likely to result in more costly resolution of financial stress.

The authors point out that although there may be some offsetting factors, (e.g. borrowing costs are likely to be higher and credit less available for younger firms, economies of scale in the cost of issuing, etc.), the weight of the theoretical and empirical evidence leads them to expect adjustment costs to increase with age.

The empirical tests in the study are based on the following two step regression estimates:

$$
\Delta L E V E R A G E_{i t}=\alpha+(1-\delta) R E V E R S I O N+\varepsilon_{i t}
$$

where REVERSION variable is the difference between the target and lagged debt ratios, based on four different proxies for target leverage.

and $\quad(1-\delta)=\phi+\gamma A G E_{t}+v_{t}$

The estimated coefficient ? is negative and statistically significant using each of the four

proxies for target leverage. The authors interpret this to mean that adjustment costs increase with age. 


\section{Comments}

A fundamental concern regarding this study relates to the definition of "target debt ratios." The target debt ratio for a firm should be defined conditional on some specific objective. For example, one could ask what the target ratio would be if a firm wants to minimize tax costs or what the target ratio would be if the firm wants to minimize total tax and financial reporting costs. Given this target debt ratio, we can ask how other costs and benefits (i.e., costs and benefits not considered in defining the target) affect the speed of adjustment towards this target. Without conditioning the target debt ratio, it is not clear how to identify the determinants of the speed of adjustment towards that target. If the firm's target debt ratio is conditioned on all the costs and benefits, then a rational firm would be at that target all the time.

One could condition target debt ratios based on results from prior research. MackieMason (1990), Dhaliwal et. al (1992,) Graham (1996) document that firms' debt ratios and their financing decisions to affect these ratios are influenced by financial distress costs, investment inefficiencies, signaling costs, etc. Why not run a standard capital structure regression that incorporates these factors? Multiply the estimated coefficients and the firm-specific values of the corresponding variables for each firm year to get the predicted debt ratio for a firm and treat the predicted as the optimal target ratio. At a minimum, there should be a control for profitability, which has enormous effects on the time-series of debt policy.

A related issue is that when firms endogenously choose to use more public debt (which the authors argue increases adjustment costs), they do so because they have become more "stable," and they do not expect to modify their capital structure very often. In other words, a firm switches to public debt when they are near their optimal capital structure. If this is true, then expected adjustment costs also decline as the firm ages.

Putting aside these issues, the first two proxies used in the paper (average over all nine years and average over historic data) are problematic. The paper's premise is that adjustment costs increase as the firm matures, which suggests that the target will also evolve, so how can using a target based on historical data make sense?

Further, as the following table shows, these two proxies are not highly correlated with the third and fourth proxies (three-year lead mean debt ratio and industry-mean debt ratio). Actually the second proxy is negatively correlated with the third and fourth proxies. Reasonable alternative proxies should be positively correlated. The fact that the paper's results are similar for various proxies, given this correlation structure, raises the possibility of some important omitted variable or other misspecification. 
Correlation Matrix for Target Debt Ratio Proxies

Based on mean values for targets shown in Table 3 of Pittman and Klassen (2001)

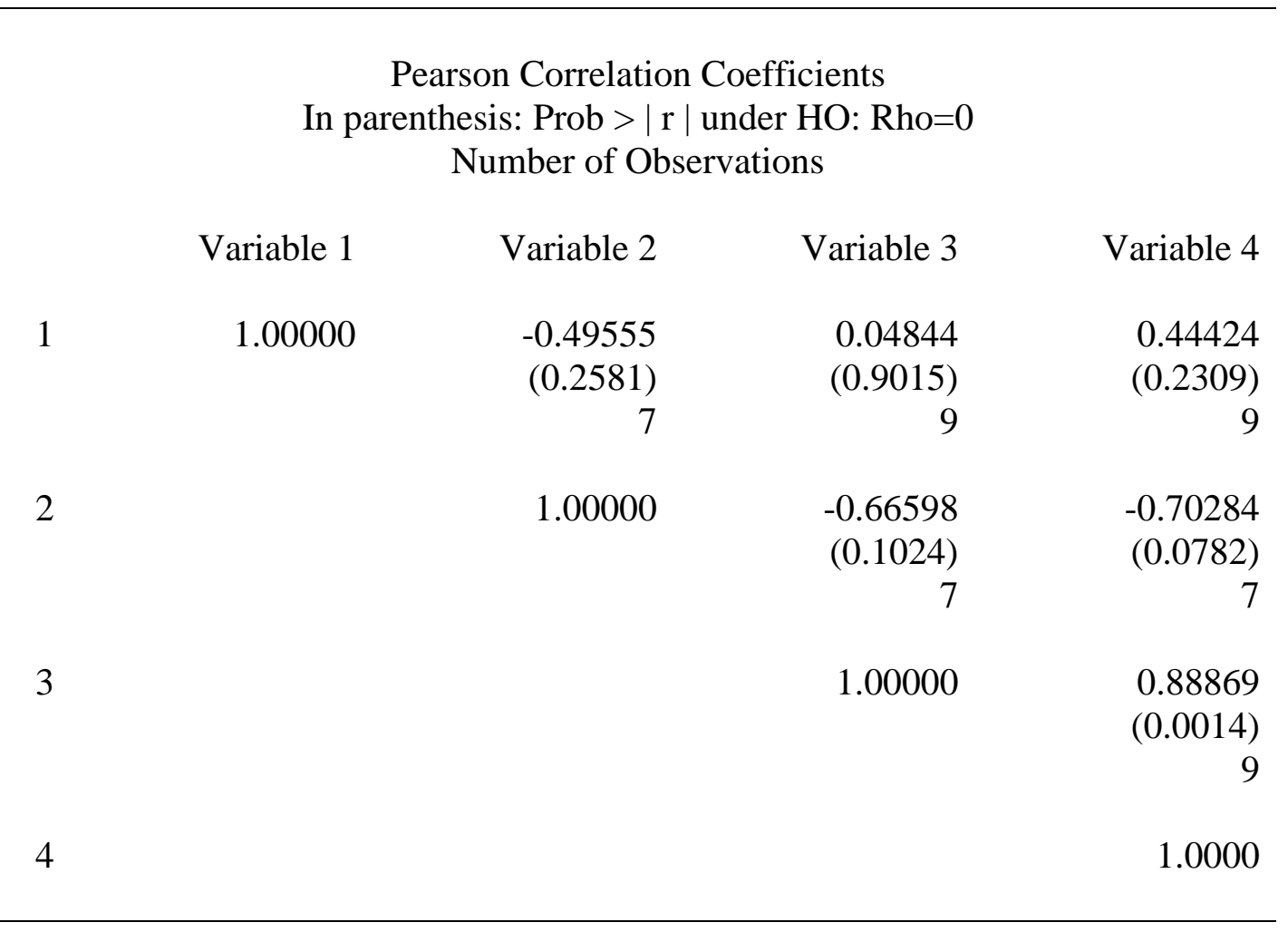

Moreover, there may be a general problem with the approach of using same-firm averages as the target. Suppose that a firm's true optimal debt ratio increases each year for five years and then levels off. If the firm hits its true optimal each year, the "true" regression coefficient is 1.0. However, using any of the paper's proxies for the target debt ratio, the estimated regression coefficients will change through time, even if it hits true optimal each year. For example, if the firm's true optimal debt ratio is $0 \%, 10 \%, 20 \%, 30 \%, 40 \%$, through its first five years and then equals $40 \%$ every year thereafter, the regression coefficient will approach zero as the optimal debt ratio levels off through time (because the dependent and independent variables will not covary towards the end of the sample).

The arguments presented in the study imply that firms should be approximately at their target ratio at the time of IPO. Similarly, they should be closer to their target ratio in earlier years than in later years. This possibility is not examined in the paper and the data presented in the paper do not allow readers to draw any inferences regarding this issue.

Table 5 in the paper presents results based on the following regression:

$$
\begin{aligned}
& \triangle \text { LEVERAGE }_{i t}=\alpha+(1-\delta) \operatorname{REVERSION}_{i t}+\beta_{1} A G E_{i t}+\beta_{2} A G E_{i t} \bullet \\
& \operatorname{REVERSION}_{i t}+\varepsilon_{i t}
\end{aligned}
$$

Motivation for this analysis is not clear. The authors (p. 17-18) state that “...the estimation of sensible proxies for target leverage is particularly difficult for this sample of maturing firms. For example, initially small and risky, these firms might systematically increase 
their debt ratios as they age, rather than revert to the specified optimum..." This issue is examined with pooled OLS results that condense the time series variation in the adjustment process into simple coefficient. It is not clear how this formulation overcomes any of the difficulties inherent in results obtained from equations (2) and (3). As the authors said in their presentation of the paper at the conference, equation (3) is simply an alternative way of estimating equations (1) and (2).

The paper is motivated as an investigation of adjustment costs, why they are important and how managers respond to them. For example, the authors quote Myers (1984) and Shevlin (1999):

"Large adjustment costs could possibly explain the observed wide variation in actual debt ratios, since firms would be forced into long excursions away from their initial debt ratios... If adjustment costs are large, so that some firms take extended excursions away from their targets, then we ought to give less attention to refining our static trade-off stories and relatively more to understanding what the adjustment costs are, why they are so important and how rational managers would respond to them." [Myers (1984), p. 578, italics added].

"I would like to see future research in the non-tax costs area are push harder to refine the tests so that we can better understand the role of non-tax costs and also begin to quantify their magnitude. I think it is well accepted that firms trade-off tax benefits with non-tax costs... I would like to see more effort expended in carefully laying out the likely non-tax costs in any setting and proxies for these non-tax costs factored into the research design." [Shevlin (1999), p. 458].

The paper does not represent a direct analysis of the issues related to adjustment costs as called for by Myers and Shevlin. Only indirect inferences regarding these issues can be drawn from the findings of the paper.

In summary, the paper deals with an important topic and is a reasonable start towards helping us understand adjustment costs. However, given difficulties inherent in measuring target debt ratios and the exclusion of various factors affecting firms' ability to change their debt ratios, results should be interpreted cautiously. 


\section{REFERENCES}

Dhaliwal, D. S., Trezavant, R., and Wang, S. 1992. "Taxes, investment-related tax shields and capital structure." Journal of the American Taxation Association 14 (Spring) 1: 1-21.

Graham, J. R. 1996. "Debt and the marginal tax rate." Journal of Financial Economics 41: 4173.

MacKie-Mason, J. K. 1990. "Do taxes affect corporate financing decisions?" Journal of Finance 45: 1471-1493. 